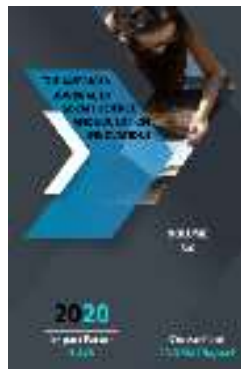

Journal Website: http://usajournalshub.c om/index,php/tajssei

Copyright: Original content from this work may be used under the terms of the creative commons attributes 4.0 licence.

\section{Problems Of Adequacy And Equivalency In Translation}

Mirabdullayeva Zulfiya Olimjonovna

Lecturer Of The Department Of Western Languages, Tashkent State University Of Oriental Studies, Uzbekistan

Bakhadirova Dildora Azodovna

Lecturer Of The Department Of Western Languages, Tashkent State University Of Oriental Studies, Uzbekistan

\title{
ABSTRACT
}

It is well known that in translation it is relatively rare for one concept to correspond to another. Experience has shown that in translation word for word, word for word, word for word can be. On this basis, when we say a lexical unit in translation, we can understand a word and a phrase, or even a phraseological unit that corresponds to a single word. In this case, a phraseological unit consisting of two or more words must correspond to the meaning of a single word. If the original word corresponds to one word in the translated language, then the meanings of the words in the two languages are considered to have the exact equivalent. Such words usually include well-known names, geographical and place names, names of enterprises, organizations, institutions, offices, ships and hotels, and so on. Equivalents are often monosemantic, that is, words with a single meaning.

\section{KEYWORDS}

Meaning, problem in translation, complex equivalents, phrase, language, imagine, concepts.

\section{INTRODUCTION}

If a single word in the language of translation is partially true to the original word, then we must think in part about the equivalents. In translation theory, three types of partial equivalents are also distinguished. This may be due to the fact that in one language there are several other word meanings in addition to the equivalent, corresponding to another 
language. One of these polysemous words is equivalent, and the rest appear as additional meanings. For example, if we take the English word "cover", it means "to cover", "to cover", "to cover", "to cover", "to cover". ymoq "," to hide "and" to cover (in the press, in an article) ".

The second variant of the semantic relationship is the phenomenon of the intersection of meanings, which corresponds in part to the equivalent word. This means that a particular word in two languages may have the same meaning or meanings, and yet they may also have inconsistent meanings. These differences in the meanings of the word are due to the fact that the languages of origin and translation belong to different families, the acquired words are derived from other languages, and a number of other linguistic and extralinguistic factors. For example, if we take the homonymous words "ball' 1 " and "ball" 2 in English, we can see the following differences: "ball'1" ball, ball "and score" 2 "ball (dance night)". In Uzbek, the word "ball" only means dance, so the context is important in finding an alternative to these words.

The third variant of the relationship belongs to the most complex type of equivalents. The point is that different peoples perceive objective reality differently and reflect it differently in language, in their own way. As you know, there are several ways to express the concept of "hand" in English. In Uzbek, the concept of "hand" is expressed in one word. In addition to the word "hand" in English, the word "arm" is also used in addition to the word mentioned above to express this concept in the language. The word "hand" is also used in a figurative sense, and although they also correspond to most of the figurative meanings in the Uzbek language, there are many differences. The opposite is true of the Uzbek language. The Uzbek words "ama", "aunt", "aunt", "uncle", "uncle", "cherry" and "cherry" are the same. settings are coming.

The translation of words belonging to the third group is of particular interest because these and similar words cause problems in the translation process. For example, if we translate the phrase "They both married their cousins," a problem arises. The problem in translation is the verb "to marry," which has two meanings. The first meaning is "marry (tir) moq", the second problematic word for translation is "cousin". It means "nephew" in Uzbek. A natural question arises here, we need to find out what kind of nephew we are talking about. In English, the word "cousin" is used for a boy's nephew and a girl's nephew: a boy's nephew (cousin), a girl's nephew (nephew). It is very difficult to translate the above sentence. To do this, you need to know the context. It is impossible to translate this sentence into Uzbek without context.

Choosing the most correct from the words that are partially equivalent is one of the current problems that need to be addressed in the focus of translation. This is directly related to the translation of words that have no equivalent (alternative) in translation. These words include names, geographical and place names, and specific words that are not used in other countries. Specific words are used as realities in the literature of translation theory. These include, on the one hand, the English lobby, muffin, drugstore, and, on the other hand, the Uzbek tandoor, somsa, girl signal, kid, and the like.

\section{MATERIAL AND METHODS}

Bilingual dictionaries are of some importance in solving lexical problems of translation. However, dictionaries usually give only alternatives to the meaning of the word. No matter how perfect a translation dictionary is, it is not possible to cover all the meanings or 
subtleties of meaning of words, because the dictionary deals with elements of a bilingual system. For translation, it is not the language systems but the speech, or more precisely, the text that is the product of the speech, that is more important. In the process of translation, the translator must determine for himself on the basis of context which meaning of the polysemous word is used.

In translation, lexical transformations are used to avoid the use of various literal, obscure combinations, and instead to translate literary, universally understood, vivid words. Lexical transformations are also referred to in translation theory as the replacement of words in context. There are five types of such transformations.

Transformations of the first type are used in the translation of words that have a broad meaning or are difficult to determine. This type of transformation is used to clarify or concretize the word originality. It is often used in the process of translating English verbs into Uzbek. English verbs are usually used in a general and ambiguous sense. This is especially evident in translation. Verbs in the Uzbek language express definite and concrete action. For example, let's analyze the plural verb "to get" in English. Context is definitely necessary to translate this verb, as there are also aspects in which its meanings are not related to each other. It is translated into Uzbek as "to take", "to catch", "to understand", "to think", "to communicate", "to reach", "to turn", "to change", "to leave" (e.g. "to turn pale") and a number of other meanings of the verb used in English with the preposition also have the property of being completely changed. For example, the verb itself has several meanings in the form "to get out". It means "to go out," "to get out," "to fall." The same can be said of a number of other English verbs. These include the verbs "to be", "to have", "to make", "to become" and others. It may be a matter of giving not only the general but also the definite meaning of a polysemous verb in translation.

It is also recommended to use transformation in the translation of broadly meaningful words such as "thing", "matter", "stuff”, "challenge" and the like, which are semantically neutral, as these words vary from context to context each time. For example, "thing" can be translated into Uzbek as a thing, a blessing, a place, a side, a side, depending on the context. Sometimes there are cases of complete omission in the translation. requires context, and the word is redundant in translation. For example, the phrase "I don't know this thing" can be translated in two different ways - "I don't know this thing" or "I don't know this thing." As can be seen from the translation, " The content of the translation was not compromised by dropping the word "thing".

The translation should take into account not only the denotative but also the connotative meaning of the words. The English verb "to employ" usually means to hire, to hire. This verb can have a positive meaning as well as a negative meaning depending on the context. Negative verbs are usually translated as very general verbs. The English word "you" deserves special mention. It should be translated into Uzbek with the pronoun "you" or "you", which differ in style and meaning of use. The translation of this word should take into account to whom the word is used, its age, gender, place in society, relationship with the speaker and the scope of the word.

\section{RESULT AND DISCUSION}

A comprehensive study of the work on the basis of knowledge of the features of two languages, work on its dictionary and realities is very important for the translator, and this 
requires him to be a scientist and researcher to some extent.

In Uzbek, there is a multi-meaning phrase "find a language". They say to find a way to someone's unlocked heart. The fact that two people work together in life, understand each other well, know each other on the problem and act accordingly is also expressed by this phrase. It also means mutual agreement, covenant. There must be a similar language between the author to be translated and his work and the translator. In this case, finding a language means a deep understanding of the author's originality and the artistic features of a particular work, and the organization of the process accordingly. Finding a language is a great creative benefit only when the author being translated and the translator love his work, knowing that it will bring great spiritual benefit to his reader.

Umberto Eco, one of the greatest writers of twentieth-century Europe, whose works have been translated into many world languages and who himself has translated and even explained what translation is, cites exemplary examples from his own creative laboratory experiments, "Exactly. Experiments on Translation." What is still the translation of the sentence in his book? begins with the question. "What does it mean to translate?" Asks Umberto Eco, who knows very well what translation is in his practice. "The first satisfactory answer may be that it is to say the same thing in another language." translation "This is a very primitive, very simple and at the same time the most accurate definition of translation. At first glance in this definition, the secret of translation - its secret as creativity and art - seems to be completely lost. But there is no denying that this simple definition is a very mysterious and very complex, difficult field of translation. Even the fact that a world-famous writer with a great deal of literary experience comes out with such a description shows that translation is a mysterious field.

Let us now consider these words in the context of our translation. So, how can the language of Borges, which is superior to the senses and knowledge, to the aristocratic courage and extreme coldness, be translated into modern Uzbek? After all, such a language did not exist in our literature, which was brought up in the spirit of centuries-old Eastern traditions! Some of the examples translated from Borges into Uzbek in recent years are very simple, and the fact that Borges is no longer Borges means that Borges has a very difficult, if not impossible, task for any translator.

When we say that translation is a mystery, we also mean events that seem impossible to translate in this way. But there is no way to overcome this wall, as there is no way to overcome it. Let us remember that the two languages - here a deep knowledge of Spanish and Uzbek - the poet Shavkat Rahmon deliberately studied Spanish to translate Lorca and translated it from Uzbek to Spanish, and most importantly - that Borges finding a sarcastic and aristocratic language. "Finding a language" can be a real guarantee of translation success. Only when a translator has as much life experience as a talented writer do his words in translation come out as clear, juicy, clear as the words of a writer. At the same time, Navoi's wise words about the famous "bright language and openness" should not be forgotten.

Only when a translator, like a writer, has the ability to do things, to have a broad understanding of the human psyche, and to have the ability to fantasize, is it possible for his work to be convincing, understandable, highly artistic, and expressive. The lack of knowledge about life, the biography of the original work and the author who created it, the lack of 
complete study and knowledge of the creative and life views of the work, the ignorance of the opinions and debates around the work - is, of course, the general art of translation. has a severe negative impact on the level of quality.

Before starting the translation, a comprehensive study of the translated work, preliminary work on its vocabulary and artistic features, specific material about the internal structure, images, socio-historical environment in which the heroes act, means of artistic expression, style, compiling references will pave the way for a successful translation.

Just as a writer collects material to write a new work, so a translator collects material and creates his own reference book about the work and its author.

Russian translator Nikolai Lyubimov used the term "writer-translator." He sees translation as inextricably linked with creativity and artistry in creativity. The word "writer-translator" or rather, "translator-writer" places a great deal of responsibility on the professional. As he recreates the work in another language, he assumes the responsibility of the writer, becoming his ambassador, his representative in another language environment. Will those who read the work accept it in the same way as those who read the work in the original? Or will the object of the work be lost in the translation and the reader will be deprived of exposure to it? The translator is responsible to the reader of another language for the artistic level and quality of the work.

\section{CONCLUSION}

Preparing for a translation is a big creative process. Before starting the translation of Leo Tolstoy's novel "War and Peace", Abdullah Kahhor visited Russia and studied the places where the events described in the play took place, the circumstances reminiscent of the environment in which the heroes lived. He took a deep look at the life that inspired Tolstoy, the source of which was the translator-writer. How did he write Leo Tolstoy's "War and Peace" in twentieth-century Uzbek? he asked. Therefore, the Russian life described by Tolstoy, all the subtleties, subtleties and beauties of the inner and outer world of the Russian people were deeply embodied in art through the means and riches of the Uzbek language.

When the author of these lines dares to translate Dostoevsky's novels into Uzbek, he realizes at every step how important and great creative it is to study the work in depth, to enter into the secrets of Dostoevsky's image, to sharpen imagination and concepts. forgave How to create the XIX century Dostoevsky language environment, its spirit? After all, the spirit and flow of the language environment of that time is very different from the spirit of our language today (from the Uzbek language environment and spirit of the 60s)? - How to get it out? When Cholpon translated Shakespeare's "Hamleff" in the 1930s, did he not archaicize the language of the work in vain?

While translating into Uzbek the Colombian writer, Nobel Laureate Gabriel Garcia Marquez's modernist fascinating novel The Autumn of Buzruk, I visited Colombia, Latin America, and witnessed the events and atmosphere of the novel. I've been reading a lot since I couldn't keep up with it, and l've had a hard time extracting color in many places. At the same time, I realized that the only way to get rid of problems is to approach the text with a natural (intuition) approach. I dared to do this great work only in the shadow of human and cultural needs, such as conveying to the Uzbek reader one of the most beautiful examples of fascinating realist literature. 


\section{REFERENCES}

1. Salomov G '. Introduction to translation theory. T.1990.

2. Salomov G. "Fundamentals of translation theory" Tashkent "Teacher", 1983.

3. Abdurahmanov "Practical grammar of the Uzbek language" Tashkent, 1992.

4. Sharipov J. Literary translations and skilled translators. Tashkent. 1977.

5. FyodorovA. Translation theory. M. 1976.

6. Andre Lefevere. Translation / History / Culture.Australia.2001.

7. EsenboevR. The art of translation. Tashkent. 1986.

8. ChernovG.V. Synchronous transfer.M. 1989.

9. K.Musaev. Fundamentals of translation theory. Tashkent 2005. 